\title{
Brown Coal Derived Humate Inhibits Contact Hypersensitivity; An Efficacy, Toxicity and Teratogenicity Study in Rats
}

\author{
C. E. J. Van Rensburg ${ }^{1}$, J. R. Snyman ${ }^{1}$, T. Mokoele ${ }^{1}$ and A. D.Cromarty ${ }^{1}$ \\ ${ }^{1}$ Department of Pharmacology,Faculty of Health Sciences, University of Pretoria, P. O. Box 2034, Pretoria, 0001, \\ South Africa
}

\begin{abstract}
Objectives:The effects of two humate products were compared to that of prednisolone on a contact hypersensitivity rat model. Methods: Rats, sensitized with dinitrofluorobenzene (DNFB), were placed on a daily oral treatment of $61 \mathrm{mg} / \mathrm{kg} \mathrm{BW}$ of humate derived from either leonardite or bituminous coal or on prednisolone at one $\mathrm{mg} / \mathrm{kg} \mathrm{BW}$ and challenged 6 days later with a topical application of DNFB to the right ear. The inflamed ears were measured daily. In a toxicity study rats were exposed to daily oral treatment of leonardite humate at $1,000 \mathrm{mg} / \mathrm{kg}$ BW for 1 month. A teratogenicity study was done where pregnant rats were treated with $500 \mathrm{mg} / \mathrm{kg} \mathrm{BW}$ on days 5 to 17 of pregnancy. Results: Only the leonardite humate compared favourably with prednisolone in suppressing contact hypersensitivity. No signs of toxicity were observed and weight gain was normal during the 6-day and 1 month treatments and during the teratogenicity study with the leonardite humate. However, the rats on the other two products experienced slower weight gain. Conclusion: The identification of a naturally occurring nontoxic compound with anti-inflammatory activity is exciting and merits further evaluation in the treatment of patients suffering from inflammatory conditions.
\end{abstract}

\section{Abbreviations \\ DNFB dinitro fluorobenzene \\ BW - body weight}

\section{Introduction}

Humic substances occur widely in nature. They are found mainly in heavily degraded peat but also in all natural environments in which organic materials and microorganisms are found, or have been present $[1,2]$.

According to a review by Schepetkin et al. [3] mud baths, rich in humic and fulvic acids, were used to treat various ailments such as rheumatic conditions during the nineteenth century. Mumie extracts have been used in the treatment of paradontosis, osteoarthrosis, rheumatoid arthritis, ankylosing spondylitis and peptic ulcers. The only experimental data that could be found in the literature was a study by Goel et al [4]. In this study the possible anti-inflammatory properties of shilajit was investigated. It was found that shilajit reduced carrageenan-induced acute pedal oedema and granuloma pouch and adjuvant-induced arthritis in rats. However no documentation could be found concerning the effects of coal-derived humates on inflammatory reactions in vivo. These preparations, especially products derived from brown 
coals, contain much higher levels of high quality humate, are easier to produce under controlled conditions and are more available in nature.

The main aim of this study was to determine whether oral treatment with humate derived from bituminous or brown coal can suppress a typical cutaneous hypersensitivity reaction in rats. The secondary outcome was to evaluate the toxicity of the humate products and in particular the brown coal derived humate in a standardised animal model as no documentation could be found on the toxicity of brown coal derived humate except for a brief report published on the web by the European Agency for the Evaluation of Medicinal Products (1999).

\section{Materials and Methods}

\section{Humate}

Two humate products were tested. A brown coal (leonardite from the Latrobe valley, Australia) derived product supplied by Unique Formulations (Milnerton, South Africa) and a bituminous coal derived product synthesized by Enerkom (Pty) Ltd. (Pretoria, South Africa) [5]. Only the soluble humates were used in the various treatments.

\section{Animals}

Female Sprague-Dawley rats of 8 to 10 weeks old (between 150 and 200g) were purchased from the National Health Laboratories Service, Rietfontein, South Africa. Scientific procedures and the code of practice for the housing and care of animals used in scientific procedures (Acts 1986 and 1989, respectively) were strictly adhered to. The rats were housed individually in plastic cages under 12-h light/dark cycles at $22^{\circ} \mathrm{C}$ with ad libitum access to water and normal rat chow. They were allowed to acclimatize for 10 days in the new environment prior to experimentation starting. Each rat was individually marked and weighed at the time of randomization and grouping. All animal experiments were carried out in a double blind placebo controlled fashion at the University of Pretoria's Biomedical Research Centre, Onderstepoort with the approval of the Animal Use and Care Committee of the University of Pretoria.

\section{Contact Hypersensitivity}

The rats were divided in four groups of 15 rats each and the experiment was carried out in two phases. The first phase used eight rats from each group and the second phase started a week later with the remaining seven rats per group. All groups were dosed with a single daily dosage by gavage $(400 \mu \mathrm{l})$ of one of the following; distilled water, a bituminous coal derived humate solution, a brown coal derived humate solution or a prednisolone solution respectively. The dosages were $61 \mathrm{mg} / \mathrm{kg}$ BW for the humates and $1 \mathrm{mg} / \mathrm{kg}$ BW for the prednisolone treatment. The humate dosage is based on that used in a previous phase I clinical trial and was administered at half the maximum dosage used in the trial [6]. The prednisolone dosage is based on the standard treatment of inflammatory conditions in daily practice [7].

On day 0 , the rats from all four groups were weighed and sensitized with 2,4-dinitrofluorobenzene (DNFB). The abdomens of the test animals were shaved and then painted with $400 \mu \mathrm{l}$ of a $2.5 \%$ solution of DNFB in acetone/olive oil (4:1) as described by van Rensburg et al. [8]. The DNBF dosages used in this study were optimized during a pilot study. After sensitization, the rats were placed on the various treatments for the full duration of the study. 
On day $6,3-4 \mathrm{~h}$ after their daily gavage, all the rats were challenged on the right ear by application to the upper surface of the ear, with $25 \mu \mathrm{l}$ of a $0.5 \%$ solution of 2,4-dinitrofluorobenzene (DNFB) in acetone/olive oil (4:1). The left ears were treated in the same way with the vehicle solution only i.e. acetone/olive oil (4:1). Three hours after challenge both the left (control) and right (challenged) ears were measured with an engineering caliper (Mitutoyo, Japan) with $20 \mu \mathrm{m}$ accuracy across the ear at a distance of $3 \mathrm{~mm}$ from the tip. The thickness of the ears was measured with a light hand and only the first readings were reported. Similar measurements of the ears were repeated after 24 and $48 \mathrm{~h}$. Treatment continued up to the last day and was administered 2-3 h before measurements were documented.

\section{Toxicity}

The rats earmarked for the toxicity study were divided into two groups of ten in each group. The control group received $1.5 \mathrm{ml}$ distilled water per day by gavage for 30 days whereas the experimental group received brown coal derived humate dissolved in the same volume of water by gavage at a dosage of $1,000 \mathrm{mg} / \mathrm{kg} \mathrm{BW}$.

Blood samples were obtained from the animals at the beginning and at the end of the study for haematological analysis using a CellDyn 3700 standard haematological analyser (Abbott $\mathrm{Lab}$ ) with a veterinary software package. The animals were weighed daily and monitored for pain and distress. At the end of the study, the animals were terminated and the organs (the liver, kidney, spleen) studied for any abnormalities.

\section{Teratogenicity}

For the teratogenicity experiment one group of ten pregnant rats received $0.7 \mathrm{ml}$ distilled water by gavage on days 5 to 17 of pregnancy whereas the treatment group of 10 pregnant rats received brown coal derived humate by gavage on the same days at a dosage of $500 \mathrm{mg}$ $/ \mathrm{kg} \mathrm{BW}$ dissolved in an equal amount of distilled water. The animals were weighed daily and monitored for pain and distress (behavioral changes). Puppies were monitored for clinical and behavioral abnormalities for a period of 2 weeks after birth.

\section{Statistical Analysis}

Statistical analysis was done using one-way ANOVA (Tukey's multiple comparison test) to determine significance between the various groups. Significance was determined at the $5 \%$ level throughout the study.

\section{Results}

Only the prednisolone and the leonardite derived humate caused a significant $(p<0.05)$ decrease in ear swelling at 3,24 and $48 \mathrm{~h}$ after challenge compared to the untreated control group (Fig.1). When the prednisolone treated group was compared to the brown coal derived humates there were no significant differences at all three time intervals. The prednisolone treated group differed significantly from the bituminous coal derived product at all three time intervals whereas the humate product derived from brown coal differed from the bituminous coal derived product at $24 \mathrm{~h}$. No signs of toxicity were observed during the 7-day treatment period with the humate products. However, the rats on prednisolone and the bituminous coal product experienced a significantly slower weight gain compared to the untreated control group (Fig. 2). 


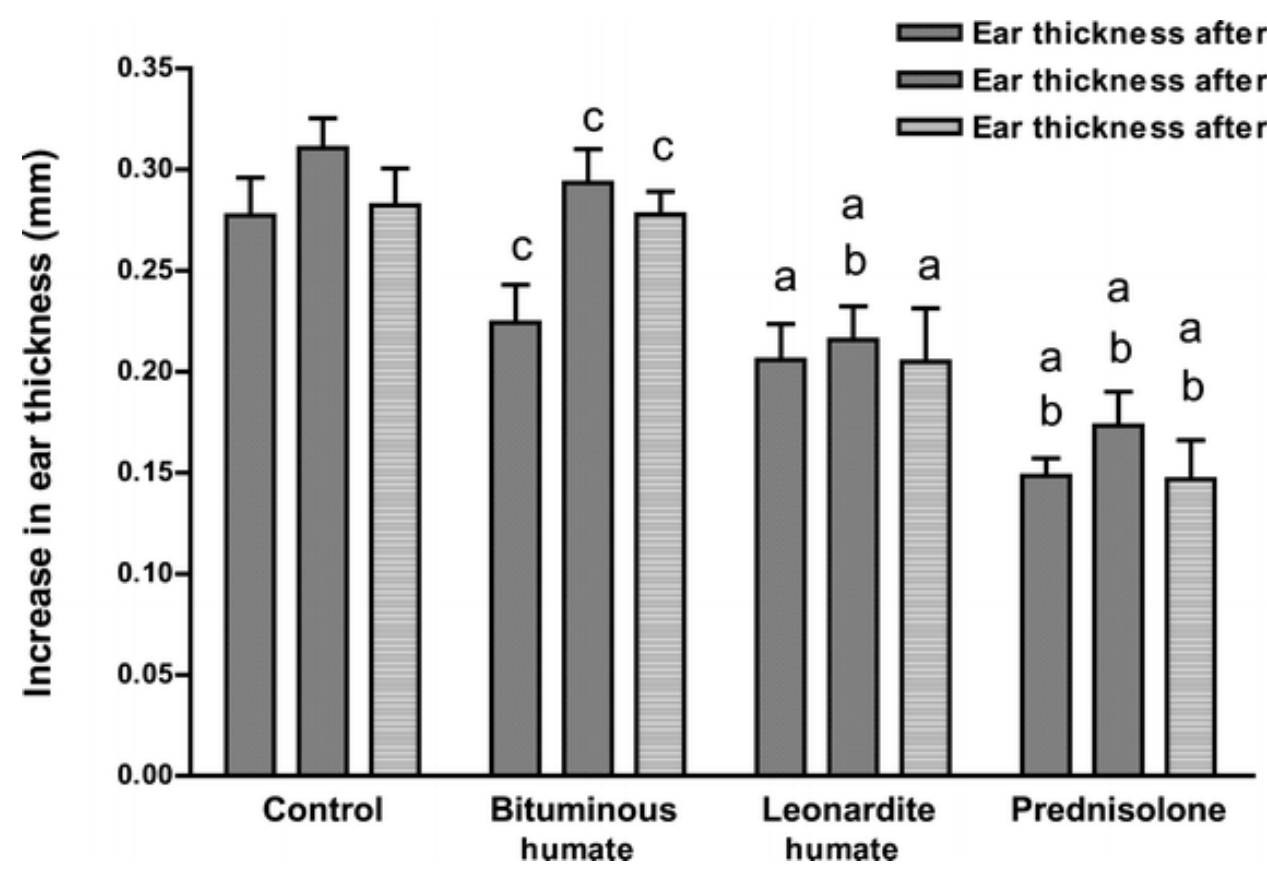

Fig. 1 Difference in ear thickness after DNFB challenge of the right ear, the left ear was treated with vehicle. Rats were treated daily for 1 week by administration by gavage: water, or $61 \mathrm{mg} / \mathrm{kg}$ BW bituminous humate, or $61 \mathrm{mg} / \mathrm{kg}$ BW leonardite humate, or $1 \mathrm{mg} / \mathrm{kg}$ BW prednisolone. a Differs significantly from control, $b$ differs significantly from bituminous coal humate, $c$ differs significantly from prednisolone, $p<0.05$ is significant.

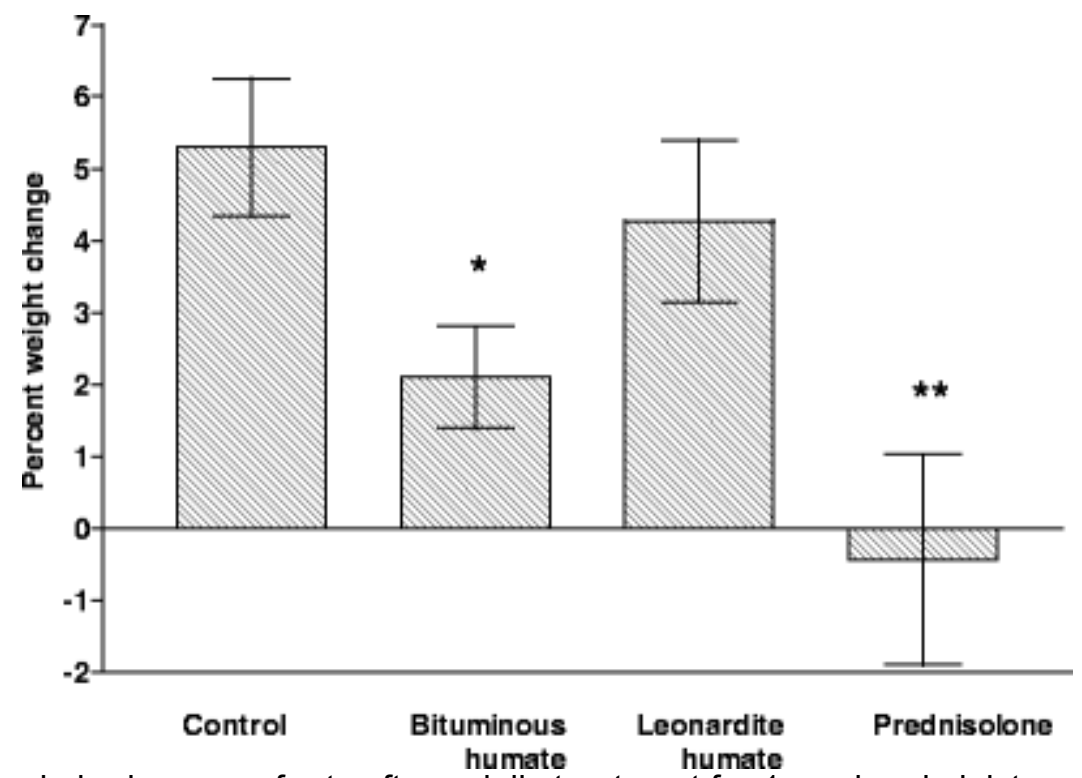

Fig.2 Changes in body mass of rats after a daily treatment for 1 week, administered by gavage, of one of the following; water; $61 \mathrm{mg} / \mathrm{kg} \mathrm{BW}$ bituminous humate; $61 \mathrm{mg} / \mathrm{kg} \mathrm{BW}$ leonardite humate; $1 \mathrm{mg} / \mathrm{kg} \mathrm{BW}$ prednisolone. Significance was calculated between untreated control values and the relevant treatment groups $\left({ }^{*} p<0.05\right)$.

No signs of toxicity were observed in the 30-day treatment study or in the teratogenicity study (results not shown) with the brown coal product. None of the animals died and there were no 
significant changes in the hematological picture of the 30-day treatment group before and after treatment or abnormalities observed in the puppies.

\section{Discussion}

According to a review written by Schepetkin et al. [3] mumie, which is a crude mixture of organic and inorganic compounds and is formed after the humification of plant material, is used in folk medicine to treat patients suffering from peptic ulcers. Plant humification products, such as topla peat preparation, Torfot and Shilijit, are complex substances and not only contains humic acid, but also benzoic acid, fulvic acid, 4'-methoxy-6-carbomethoxybiphenyl and tirucallane-type triterpenoids which could have contributed to its reported medicinal properties [3]. Very limited in vivo data is available on the medicinal application of humic acid derived from coal. Some safety data for humic acid derived from bituminous coal has been established in patients suffering with HIV infection who ingested these substances as tonics [6]. In the latter study patients were treated with dosages of humic acid up to $8 \mathrm{~g}$ per day for 2 weeks with no detrimental effects.

Potassium humate derived from bituminous coal did not inhibit the inflammatory reaction caused by DNBF in this study. Although the basic compounds of the two humate products are the same, thermogravimetric analysis revealed differences in terms of the volatile compounds between the samples (results not shown). These subtle differences may explain the above findings.

Inflammation induced by DNBF is mostly associated with a delayed type hypersensitivity reaction [9]. DNBF acts as a hapten as it reacts with aminoacid side chains of cell surface proteins where it is processed by Langerhans cells which migrate from the epidermis to regional lymphnodes. After maturation they are responsible for the development of specific CD4 effector and memory T-cells which will be stimulated upon reintroduction of a second exposure of DNBF releasing pro-inflammatory cytokines at the site of challenge. This will lead to a cascade of events resulting in erythema, edema, vascular leakage and infiltration of cells such as neutrophils, monocytes and T-cells.

In this study we determined that DNBF-induced contact hypersensitivity in rats can be reduced with brown coal derived humate at a dosage of $61 \mathrm{mg} / \mathrm{kg}$ BW, administered by gavage directly after the sensitization step and continued for 8 days. The anti-inflammatory effects of humate might be due to either an inhibition of the sensitization step or an inhibition of the challenge step or both. However the intrinsic mechanism by which it affects cellular function still needs to be clarified. It has been demonstrated that humate has a strong affinity to bind to several compounds, such as herbicides [10] and mutagens [11, 12]. The possibility exists that humate adsorbs pro-inflammatory molecules such as cytokines and complement factors. Inhibition of CR3 expression by potassium humate derived from bituminous coal has been reported by Jooné and van Rensburg [13] and could possibly explain, at least in part, the anti-inflammatory properties of humates as an over-expression of CR3 is associated with the production of a multitude of cytokines, reactive oxygen and nitrogen intermediates and proteolytic enzymes that can cause tissue injury and even lead to autoimmune diseases [14]. This needs to be investigated further. 
The slower weight gain caused by both prednisolone and the humate derived from bituminous coal may indicate that these compounds have pathological effects on the rats which could be partially due to the allergen challenge combined with the toxicity of the compounds.

In this study we found that brown coal derived humate at $1,000 \mathrm{mg} / \mathrm{kg} \mathrm{BW}$ per day has no effect on any of the safety parameters when administered by gavage for one month nor did $500 \mathrm{mg} / \mathrm{kg} \mathrm{BW}$ have any effect on pups when administered to pregnant female rats on days 5 to 17 of pregnancy. The lack of toxicity and teratogenicity documented in this study confirm the summary report on a brown coal derived humate released by The European Agency for the Evaluation of Medicinal Products in 1999. This study describes a similar chronic toxicity and teratogenicity study done on rats, using the same dosages as in this study. In addition they also reported a LD50>11500 mg/kg BW obtained in an acute toxicity test in rats.

In summary: Brown coal derived humate inhibited the cutaneous hypersensitivity reaction in rats similar to a known anti-inflammatory glucocorticosteroid (i.e. prednisolone) but with no signs of systemic toxicity. This warrants further evaluation of brown coal derived humate in humans as anti-inflammatory agent.

\section{References}

1. Visser, S. A. 1973. Some biological effects of humic acids in the rat. Acta. Biol. Med. Germ. 31:569-581

2. Hartenstein, R. 1981. Sludge decomposition and stabilization. Science 212:743-749.

3. Shepetkin, I., A. Khlebnikov, and B. S. Kwon. 2002. Medical drugs from humus matter: Focus on mumie. Drug Dev. Res. 57:150-159.

4. Goel, R. K., R. S. Banerjee, and S. B. Achrarya 1990. Antiulcerogenic and antiinflammatory studies with shilajit. J. Ethnopharmacol. 29:95-103.

5. Bergh, J. J., I. J. Cronje, J. Dekker, T. G. Dekker, L. M. Gerritsma, and L. J. Mienie. 1997. Non-catalytic oxidation of water-slurried coal with oxygen: identification of fulvic acids and acute toxicity. Fuel 76:149-154.

6. Botes, M. E., J. Dekker, C. E. J. van Rensburg. 2002. A phase I trial with oral oxihumate in HIV-infected patients. Drug Dev. Res. 56:34-39

7. Dollery, C. 1999. Prednisolone and prednisone. Therapeutic Drugs, 2nd ed. Churchill Livingstone, Edinburgh, pp. 192-193.

8. Van Rensburg, C. E. J., S. C. K. Malfeld, and J. Dekker. 2001. Topical application of oxifulvic acid suppresses the cutaneous immune response in mice. Drug Dev. Res. 53:29-32

9. Klimuk, S. K., S. C. Semple, P. Scherrer, M. J. Hope. 1999. Contact hypersensitivity: a simple model for the characterization of disease-site targeting by liposomes. Biochim. Biophys. Acta 1417:191-201.

10. Nègre, M., H. R. Schulten, M. Gennari, D. Vindrola. 2001. Interaction of imidazolinone herbicides with soil humic acids. Experimental results and molecular modeling. J. Environ. Sci. Health. B 36:107-125.

11. Sato, T., Y. Ose, H. Nagase, and K. Hayase. 1987. Adsorption of mutagens by humic acid. Sci. Total Environ. 62:305-310.

12. Cozzi, R., M. Nicolai, P. Perticone, R. De Salvia, F. Spuntarelli. 1993. Desmutagenic activity of natural humic acids: inhibition of mitomycin $C$ and maleic hydrazide mutagenicity. Mutat. Res. 299:37-44.

13. Jooné, G. K., and C. E. J. van Rensburg. 2004. An in vitro investigation of the anti-inflammatory properties of potassium humate. Inflammation 28(3):69-174.

14. Weiss, S. J. 1989. Tissue destruction by neutrophils. New Engl. J. Med. 230:365-376. 